\title{
RAÇA, ETNICIDADE E RELIGIÃO: DAS CIÊNCIAS SOCIAIS ÀS CIÊNCIAS DA RELIGIÃO
}

\author{
Milena Regina de Paula Silva ${ }^{1}$
}

\section{RESUMO}

O presente trabalho visa realizar um pequeno levantamento de pesquisas na área das Ciências da Religião e demais campos de estudos no que se refere à religiosidade do negro e sua constituição identitária étnica. Sabemos que a temática da identidade negra nas ciências sociais foi abordada de muitas formas, o que nos suscitou a pergunta: qual é a situação de estudos sobre raça e etnia negra nas ciências da religião? Tendo em vista a importância do debate das questões raciais no contexto institucional religioso, realizamos um breve levantamento quantitativo em algumas das principais revistas acadêmicas das Ciências da Religião. Utilizamos como critério de seleção dos artigos, a presença ou ausência de temáticas sobre racismo e identidade negra abordadas nas publicações, incluindo atemática das experiências religiosas dos negros desde as Igrejas Pentecostais, passando pelas instituições católicas e de matriz africana. A metodologia utilizada na pesquisa é quali-quantitativa.

Palavras-chave: Ciência da Religião. Religiosidade. Identidade étnica negra.

${ }^{1}$ Graduanda em Ciências Humanas pela Universidade Federal de Juiz de Fora - UFJF. E-mail: milenaregina19@gmail.com Artigo apresentado ao Bacharelado Interdisciplinar em Ciências Humanas como requisito parcial para obtenção do grau de Bacharel. Orientador: Prof. Dr.Emerson José Sena da Silveira. 


\section{INTRODUÇÃO}

Tendo em vista a importância da demarcação identitária para grupos étnicos, buscamos neste trabalho selecionar as principais revistas eletrônicas acadêmicas com o intuito de diagnosticarmos como vem sendo feito o debate sobre negritudes e etnicidades ${ }^{2}$ no que concerne às religiosidades em suas diferentes manifestações.

Para tanto, abordamos, num primeiro momento, as implicações que permeiam o tema da constituição identitária negra. Posteriormente, refletimos com base nas principais contribuições dos estudos de Ciências da Religião a respeito das instituições religiosas enquanto potencial de mudança nas relações sociais, políticas e culturais, assegurando a identidade étnica negra - como nas religiões afro-brasileiras - ou propondo novas formulações. Em última instância, um pequeno levantamento de publicações na área da Ciência da Religião e demais campos de estudos no que se refere à religiosidade do negro e sua constituição identitária étnica, dados referentes à cor e formação acadêmica dos pesquisadores cuja temática racial foi abordada alicerçada aos estudos sobre as diferentes manifestações religiosas.

É importante salientarmos que na primeira parte da pesquisa utilizamos o método histórico, para melhor compreendermos os acontecimentos em seus processos históricos, verificando as influências que tais circunstâncias ainda exercem sobre a realidade atual. Já na segunda parte da pesquisa, consiste na coleta de dados quali-quantitativos e estatísticos no que se refere às publicações dos periódicos nas revistas eletrônicas, à ênfase de formação acadêmica dos pesquisadores e a cor, relacionando os fenômenos entre si.

Durante o desenvolvimento da pesquisa, encontramos algumas dificuldades para coletarmos os dados referentes à cor e formação dos pesquisadores, pois essas informações foram adquiridas pelo currículo lattes (Plataforma Lattes) de cada um que a mantêm atualizado. Referente às revistas e periódicos analisados, obtivemos todas as informações quantitativas de cada uma por meio dos sites. Foram seis revistas eletrônicas examinadas, sendo elas: Religião e Sociedade na qual só está disponível para acesso os periódicos desde 2007 -, Rever (Revista

2 Santos (2010) afirma sobre etnia ou etnicidade como sendo tudo o que engloba concepções e crenças religiosas, práticas culturais, línguas e representações de mundo partilhadas por um determinado grupo. 
de Estudos da Religião), PluraAbhr (Revista de Estudos de Religião), Anpuh (Associação Nacional de História), Horizonte (Revista de Estudos de Teologia e Ciências da Religião) e Numen ${ }^{3}$ (Revista de Estudos e Pesquisa da Religião). Nosso objetivo inicial também era realizar um levantamento dos artigos publicados nos congressos da Anptcre (Associação de Pós-graduação e Pesquisa em Teologia e Ciências da Religião) e Soter (Sociedade de Teologia e Ciências da Religião). Porém, devido à extensão dos relatórios e a ausência de tempo, não pudemos concluir esta etapa.

Os critérios para a seleção dos artigos que continham a temática religiosidade e identidade negra foram desde a análise dos resumos e palavras-chave dos artigos, até os títulos, facilitando e direcionando a pesquisa que tem cunho exploratório. Sendo assim, procuramos também por meio da identificação das citações de palavras tais como negritude, racismo, religiões e etnicidades

${ }^{3}$ Religião e Sociedade é uma revista semestral dedicada ao tema da religião em todas as suas possibilidades de relações com a sociedade. Está aberta a todos e quaisquer enfoques, tendências, perspectivas e propostas de interpretação, inclusive a diálogos ou confrontos interreligiosos, partindo do complexo de disciplinas das humanidades e ciências sociais. Foi criada em 1977 pelo centro de Estudos da Religião (CER) e pelo Instituto de Estudos da Religião (ISER), o qual atualmente a edita. Disponível em: <http://www.scielo.br/revistas/rs/paboutj. htm > Acesso em: 26/01/2017.

A REVER - Revista de Estudos da Religião é uma publicação semestral do Programa de Pós-graduação em Ciências da Religião, da Pontifícia Universidade Católica de São Paulo, classificada como A2 no QUALIS de sua área (Teologia/ Ciência da Religião. Seus objetivos são informar o leitor sobre a pesquisa corrente e propiciar uma discussão metateórica em torno da Ciência da Religião tanto no âmbito nacional quanto no nível internacional. Sua primeira publicação foi no ano de 2001. Disponível em:<http://revistas.pucsp.br/index.php/rever>Acesso em: 26/01/2017. Revista PLURA, Revista de Estudos de Religião, é de uma iniciativa da Associação Brasileira de História das Religiões, ABHR. Trata-se de um espaço dedicado à publicação da pesquisa acadêmica acerca da religião, em suas diversas manifestações e abordagens. Sua primeira publiçação foi no ano de 2010. Disponível em: <http://www. abhr.org.br/plura/ojs/index.php/plura/index>

ANPUH - Associação Nacional dos Professores Universitários de História foi fundada em 1961 no estado de São Paulo. A entidade trazia na sua fundação a aspiração da profissionalização do ensino e da pesquisa na área de história, opondo-se de certa forma à tradição de uma historiografia não- acadêmica e autodidata ainda amplamente majoritária à época. O quadro atual de associados da ANPUH reflete a diversidade de espaços de trabalho hoje ocupados pelos historiadores em nossa sociedade. A abertura da entidade ao conjunto dos profissionais de história levou também à mudança do nome que, a partir de 1993, passou a se chamar Associação Nacional de História. Disponível em:<http://site.anpuh.org/index.php/quem-somos> Acesso em: 26/01/2017.

Horizonte - Revista de Estudos de Teologia e Ciências da Religião é uma publicação trimestral do Programa de Pós-graduação em Ciências da Religião, da Pontifícia Universidade Católica de Minas Gerais, classificada como A1 no QUALIS de sua área (Filosofia, subcomissão Teologia). Primeira publicação em 1997. Disponível em:<http:// periodicos.pucminas.br/index.php/horizonte/issue/archive?issuesPage=5\#issues >Acesso em: 26/01/2017.

Numen: Revista de Estudos e Pesquisa da Religiãoé uma publicação acadêmica do Programa de Pós-Graduação em Ciência da Religião (PPCIR) da UFJF. A proposta da revista Numen é ser um espaço para a divulgação de pesquisas, preferencialmente de doutores, relevantes para a compreensão da religião, com abertura para perspectivas diversas. Numen não se concebe como veículo de divulgação religiosa, mas sim de compartilhamento de estudos comprometidos com a abordagem necessária no âmbito de estudos de pós-graduação. Primeira publicação em 1998. Disponível em: https://numen.ufj.emnuvens.com.br/numen/issue/archive> Acesso em: 26/01/2017. 
selecionar os periódicos.

Conforme iremos abordar, a discriminação e o preconceito racial ainda fundamentam as relações sociais no Brasil, alimentados pela cultura do racismo. Dito isto, é notória a importância e visibilidade que os debates sobre constituições étnicas negras deveriam ter nos meios acadêmicos, contribuindo com a análise das diferentes resistências políticas negras em todas as esferas da vida social. Sabendo que a religião é um fenômeno social que influencia a vida de todos, procuramos visualizar como tem sido a contribuição das Ciências da Religião para estes estudos.

Assim, sabendo da diversidade cultural que forma a identidade nacional e étnica brasileira, iremos pontuar as principais abordagens sobre estes temas, objetivando alcançarmos o debate sobre a importância que os estudos étnicos e raciais devem ocupar nas Ciências da Religião.

\section{IDENTIDADE NEGRA: ENTRE AS CONTRADIÇÕES E AS AFIRMAÇÕES ÉTNICAS}

Com o intuito de abordarmos brevemente as problemáticas que envolvem as identidades étnicas e culturais, iremos refletir sobre o que antropólogos, sociólogos e pesquisadores nos deixaram como contribuição teórica para compreendermos minimamente a temática. Assim, iniciaremos com os aspectos que caracterizaram a formação da identidade nacional do povo brasileiro até chegarmos ao debate sobre demarcações identitárias étnicas negras.

Schwarez (1999), em seus estudos sobre a questão racial e étnica alega que desde os primeiros anos pós-independência o processo de criação da identidade nacional se tornou um dos principais ideais políticos do período. Sendo assim, a questão da identidade étnica e cultural do Brasil se tornou estratégica, tendo em vista a formação do Estado sem a consolidação de uma nação (sociedade civil).

No século XIX, o Darwinismo Social de Spencer se popularizou entre cientistas sociais e antropólogos com um discurso que servia como mecanismo de manutenção à desigualdade de raças e classes sociais com os atributos negativos que tal teoria concedia aos grupos sociais considerados inferiores (SEYFERTH, 1995). Entretanto, tendo em vista que esses argumentos biológicos sobre as raças seriam um entrave para a formulação de uma identidade nacional brasileira, a tese da degeneração das raças e degradação da nação devido à miscigenação cai em descrédito. 
Assim, nos anos 1930, além de argumentos que negavam o conflito entre as raças, passou-se a ter o repúdio a teorias darwinistas do século XIX que viam a miscigenação como degeneração das raças (SCHWAREZ, 1999). Com isso, foi com Gilberto Freyre, no livro Casa Grande e Senzala, que a nacionalidade brasileira foi marcada pelo distintivo da mestiçagem.

Para o Freyre, apesar de toda violência sofrida pelos negros e indígenas no período da escravatura, a mestiçagem trouxe uma cultura com aspectos bem específicos, tanto positivos, quanto negativos que pautam comportamentos e ações dos brasileiros. Assim, Freyre afirma que as bases da sociedade brasileira foram formadas numa estrutura agrária, escravocrata na técnica de exploração econômica e de composição híbrida - ou seja, índios, negros e portugueses. Consequentemente, as contribuições étnicas e culturais dos negros de diáspora, dos índios e dos portugueses promoveram relações antagônicas entre esses grupos, mas que apesar disso, se convergia para a miscigenação que tornava a identidade do brasileiro singular.

Acrescidos a este mito das três raças, inicia-se, segundo Schwarez (1999) um processo de desafricanização dos elementos culturais africanos, pois estes são simbolicamente clareados, tendo a imagem do mestiço como síntese do brasileiro que não se aproxima dos traços negróides, mas também não é branco. Nesse sentido, a existência do mestiço representa dois aspectos: o de obstáculo classificatório de raças; e a inexistência de conflito entre as raças.

Como conseqüência, há a inibição de conflitos simbólicos e materiais ao sugerir a convivência harmoniosa entre as três raças, outorgando lugares sociais determinados na estrutura da sociedade aos negros e indígenas.

Em contrapartida, embora este construto ideológico que concedia à mestiçagem principal meio para se resolver o "problema do negro" tenha sido muito bem difundido, este engodo não foi comprado por todos. Houve muita resistência da própria população negra, que repudiava qualquer idéia que viesse afirmar a existência de uma harmonia na relação entre as raças e a inexistência do racismo (SANTOS, 2010).

Um bom exemplo disso foi a atuação da Frente Negra Brasileira (FNB) que, nos anos 30, organizou jornais e congressos chamando a atenção para os problemas que afligiam a "população de cor": exclusão econômica, analfabetismo massivo e mobilidade social negativa (SANTOS, 2010, p. 05). 
Segundo Guimarães (2012), W. E. B. DuBois foi o primeiro a teorizar "raça negra" não como fator biológico, mas próximo ao que seria chamado de "cultura" mais tarde por Franz Boas. $\bigcirc$ objetivo desse intelectual era desenvolver meios para a emancipação cultural independente de negros americanos.

Analisando o processo de ressignificação das palavras "raça", "negro", "classe", "homens de cor" e "preto" num percurso histórico no Brasil, Guimarães (2012) estudou as transformações semânticas dessas palavras para a reconstrução da identidade, auto-estima e fortalecimento do grupo oprimido. Nesse sentido, Guimarães (2012) pontua três utilizações da palavra "negro" nos diferentes períodos: utilizado para designar pessoas de cor mais escura (séc. XVI/ XVII); utilizado para designar pessoas e povos de status social ou constituição biologia inferior (séc. XIX) e utilizada como autodefinição dos povos em seus movimentos de libertação colonial e de recuperação da auto-estima - identidade, ressignificação (séc. XX/XXI).

Contudo, com os processos de ressignificação das terminologias aliado a politização dos negros, Santos (2010) afirma que foi a organização Frente Negra Brasileira quem revalorizou a palavra negro de forma a exaltar positivamente este grupo. Assim, "desde então, negro deixou de ser sinônimo de escravo, de inferioridade racial, passando a ser visto como identidade positiva de pessoas denominadas como pretas, pardas, mulatas, mestiças (...)" (SANTOS, p. 06, 2010).

Nos anos 1950/60, junto a Oracy Nogueira e Florestan Fernandes, Pierson, (1951), Willems (1948), Mussolini (1952) e Antônio Candido (1964) elaboraram seus estudos sobre relações raciais e étnicas pelo viés marxista de perspectiva sociológica, nomeado estudos de comunidade. Contudo, estes teóricos acreditavam em desigualdades raciais sustentadas por desigualdades sociais, sendo a supressão destas solucionada por meio da modernização/ democratização das instituições, não por meio do enfrentamento de suas especificidades (SCHWAREZ, 1999).

Nesse sentido, Seyferth (1995) problematiza a respeito da centralidade em que a variante classe social ocupa nos estudos sobre as questões raciais, obscurecendo todos os outros fatores. Assim, afirma que é importante ressaltar

${ }^{4}$ O sociólogo, historiador e ativista William Edward Burghardt Du Bois, nascido em 23 de fevereiro de 1868, no estado de Massachusetts (EUA), foi, ao longo da primeira metade do século XX, um dos principais nomes da luta pela justiça social e contra o racismo e é, até hoje, celebrado como o pai do movimento de tomada de consciência pelo povo negro da constante violência e violação de direitos a que era submetida. Disponível em:<http://www.palmares.gov.br/?p=40672 > Acesso em: 28/01/2017. 
que o negro é marginalizado, em primeira instância, porque é negro. Portanto, nem miscigenação e tampouco a ascensão social são capazes de anular o preconceito racial no Brasil.

Nenhum indicador da posição de classe é capaz de suprimir o estigma da raça numa sociedade onde os lugares sociais atribuídos aos não brancos são o elevador de serviço, a cozinha ou, de forma simbólica, a senzala (...) (SEYFERTH, 1995, p. 194).

Posteriormente, num cenário de grandes tensões políticas dos anos 1960/70, funda-se o MNU ${ }^{5}$ em São Paulo. Com isso, diversos intelectuais negros como Clóvis Moura (1977, 1981) e Abdias do Nascimento (1978) publicaram livros cuja principal análise centrava no desvendamento da discriminação racial e suas nuances, racializando mais os questionamentos de produções acadêmicas anteriores.

No que se refere aos estudos sobre etnicidades, os ensaios de F. Barth (1969) são relevantes. A autora acrescentou aos vieses biológicos e culturais a dimensão social. A identidade passa, com isso, a ser compreendida como "grupos de relação" que se dialogam e organizam socialmente, cujos membros se identificam. Assim, a autora concebia a identidade como algo dinâmico, sujeito a ressignificação e mudança. Ou seja, "a identidade não é, portanto, atemporal e imutável em seus traços culturais (...). Ela resulta da ação e reação entre esses grupos e outros, num tipo de jogo que não pára de se alterar" (SCHWAREZ, p. 295, 1999).

Segundo Schwarez (1999), Barth também identifica o traço decisivo da identidade, que repousa sobre a auto-atribuição ou da atribuição de outros a um grupo étnico. Outro estudioso sobre o tema foi Cunha (1985), que afirmou ser por meio da tomada de consciência das diferenças que a identidade se forma, preservando a memória e promovendo o esquecimento. Assim, Schwarez (1999) reconhece que tais análises contribuíram para o entendimento de que não há identidades essenciais, mas identidades entendidas enquanto 'construto social'.

Santos (2010) afirma sobre etnia ou etnicidade como sendo tudo o que engloba concepções e crenças religiosas, práticas culturais, línguas e representações de

${ }^{5}$ Para Cardoso (2013) no que tange a luta contra a opressão racial, destaca-se a fundação em 1978 do Movimento Negro Unificado (MNU), que embora tenha sido fundada no contexto de ditadura militar, conseguiu estabelecer mudanças sólidas reinvindicar políticas direcionadas à população negra no país. CARDOSO, Franciele. Memória e Luta Política do Movimento Negro Unificado, 2013. 
mundo partilhadas por um determinado grupo. No que tange a identidade étnica, pode-se dizer que esta, está sempre relacionada à cultura de um povo. Nesse sentido, para o autor, o que chamamos de identidade é a cultura de um povo alicerçada em práticas culturais. Sendo assim, toda a identidade é construção social e histórica, sendo a demarcação de identidades ferramenta que pode objetivar auto-proteção, defesa de interesses e reversão da opressão.

Outro teórico que trouxe contribuições para o debate das etnicidades foi Carvalho (2006), que interpretou o racismo brasileiro por meio da noção de "duplo vínculo". Para este autor, a maneira com a qual as relações sociais se estruturaram no pós- abolição se caracterizaram pela ausência de demarcação da diferença, o que dificultou a construção de uma identidade coletiva para o negro e velou o racismo. Nesse sentido, como salienta Kabengele Munanga (2008):

[as] elaborações especulativas e ideológicas vestidas de cientificismo dos intelectuais e pensadores dessa época ajudariam hoje, se bem interpretadas, a compreender as dificuldades que os negros e seus descendentes mestiços encontram para construir uma identidade coletiva, politicamente mobilizadora (MUNANGA, 2008, p. 48).

Assim, afirma Marçal (2012) que no Brasil, oposto de outros países multirraciais, aos negros foi negado o direito de se ter uma identidade para afirmar ou negar. Contudo, reitera que "a ausência de conflitos raciais pode evidenciar não a inexistência do racismo, mas o grau de opressão material e simbólica em que a maioria da população negra vivencia no Brasil" (MARÇAL, p. 52. 2012).

Diante disso, configura-se a dificuldade de solidariedade entre o grupo social e barreiras para se constituir uma identidade coletiva positiva do negro, prejudicando a saúde metal e psicológica dos indivíduos pertencentes a este grupo estigmatizado e marginalizado. Portanto, numa sociedade multirracial e multicultural, torna-se cada vez mais imprescindível a reivindicação do direito à diferença, levantando como proposta contra-hegemônica as particularidades peculiares a cada grupo étnico afirmando criticamente a diversidade (MARÇAL, 2012).

Para tanto, faz-se necessário o agrupamento dessas minorias, de modo a se organizarem coletivamente objetivando inserir suas questões sociais e materiais nas pautas políticas que ainda não os inclui devidamente. Assim, o investimento em programas governamentais que construam uma imagem negra positiva e 
Raça, etnicidade e religião, pp. 132 - 155

políticas de ação afirmativa e promoção da igualdade racial são imprescindíveis em uma sociedade que preze cessar as desigualdades sociais e estruturantes, possibilitando a equidade entre todos os grupos (SANTOS, 2010).

Constata-se, portanto, que a superação das pseudociências das raças, que negligenciava a diversidade humana, levou posteriormente a diferentes ideologias políticas de valorização das identidades e culturas. Dessa forma, "todas as identidades sociais são ou podem ser instrumentalizadas politicamente, ou seja, serão utilizadas direta ou indiretamente visando a determinados fins." (SANTOS, 2010, p. 09,).

Entretanto, esta instrumentalização política das identidades étnicas pode ser desenvolvida em um contexto religioso - como veremos posteriormente-, tendo em vista a influência que a religiosidade exerce sobre valores sociais, morais, comportamentos e atitudes do praticante.

Dessa forma, ao ampliarmos as teses sobre estratégias de constituição identitária negra, observaremos que em relação às religiões, há uma pluralidade de vivências religiosas negras a serem analisadas, pois os contextos sociopolíticos e religiosos que este grupo étnico se encontra são distintos, mesmo fazendo parte de uma mesma coletividade.

Sendo assim, iremos, no próximo item, debater sobre as diferentes experiências religiosas vivenciadas pelo grupo étnico negro, que podem nos sugerir novas fórmulas de construção da identidade e de novas definições sobre a negritude nos cenários religiosos brasileiros.

\section{PRINCIPAIS ABORDAGENS SOBRE NEGRITUDE E RELIGIOSIDADE NAS CIÊNCIAS DA RELIGIÃO}

Visando problematizar sobre o sentimento de pertença, religiosidade e identidade étnica/cultural negra presente na Comunidade remanescente de quilombo São João Batista, Silva, Ávila e Maciel (2010) ressaltam o sincretismo religioso tanto nas religiões de matriz afro (catequização/cristianização) quanto da Igreja Católica local, modificando e alterando ritualísticas e liturgias de cada dimensão religiosa (Católica e Africana).

Nesse sentido, para os autores o sincretismo religioso consistiu num fenômeno concretizado no período do Brasil Colônia e Império, no qual religiões de matriz africana se adaptaram aos rituais de fé católica. Como resquício da imposição dos costumes e valores morais europeus, predomina ainda nos dias de hoje uma 
intolerância à religiosidade e cultura afrodescendentes.

Contudo, há de se evidenciar os processos de resistência vindos dos elementos religiosos dos africanos no período escravagista. Com isso, salientam que a manifestação religiosa de cada povo que habitou o Brasil em sua formação (negros, indígenas e europeus) teve como conseqüência o sincretismo religioso e cultural, dando origem as religiões afro-brasileiras (SILVA, ÁVILA e MACIEL 2010).

No que diz respeito à identidade religiosa da comunidade São João Batista, esta se diz católica. Porém, os elementos religiosos de matriz cultural africana estão fortemente enraizados naquele contexto. O início da festa de São João Batista foi no ano de 1922 na cidade de Coxim. A festa foi realizada após uma promessa feita a São João Batista pela matriarca Maria Rosa Anunciação, cujo pedido era referente à saúde de seu filho José Soares Magalhães, que havia nascido prematuro e doente. Com a recuperação da saúde deste, a matriarca prometera rezar o terço e fazer uma festa enquanto vivesse em homenagem a São João Batista. Até os dias atuais, esta homenagem ao Santo católico é comemorada, transformando-se em tradição. A comemoração é realizada nos dias 23 e 29 de junho na Associação Familiar Comunidade Negra São João Batista (AFCN) 6 situada no Bairro Santa Branca e aberto a toda comunidade (SILVA, ÁVILA e MACIEL 2010).

Os autores pontuam alguns aspectos que diferenciam à missa afro de uma missa comum, pois durante as ritualísticas identifica-se claramente o resgate de valores culturais africanos. Padre Josuel destaca alguns, sendo eles: a natureza, os antepassados, a festa, a dança e a comida.

(...) durante todo o ritual litúrgico está presente o som dos atabaques e o compasso de danças e saudações de paz com a palavra "axé"; as pessoas permanecem descalças, em contato com a terra; as vestes têm motivos africanos; os cantos executados fazem alusões à cultura e à história dos negros; as figuras de Zumbi e a Negra Mariama são lembradas em vários

\footnotetext{
${ }^{6}$ A Associação Familiar Comunidade Negra São João Batista (AFCN)é uma associação civil sem fins lucrativos cujos associados são membros das famílias Anunciação e Bispo que tem dentre seus principais objetivos: a preservação das raízes culturais; estudo e divulgação da cultura afro-brasileira; a elaboração e execução de projetos que promovam maior autoestima e desenvolvimento socioeconômico e educacional para Comunidade, como também, para outras comunidades afrodescendentes e acima de tudo, buscando o fortalecimento e a união entre as famílias (SILVA, ÁVILA e MACIEL 2010).

${ }^{7}$ Negra Mariama: ícone maior da espiritualidade afro no que se refere à devoção a Maria (Nossa Senhora). Representa a opção de Deus para com os negros, os pobres mais pobres nos tempos da escravidão, quando ela apareceu toda negra (Silva, 2007).
}

CSOnline - Revista Eletrônica de Ciências Sociais, Juiz de Fora, n. 28 (2019) 
momentos (SILVA, ÁVILA e MACIEL 2010, p. 55).

Os autores afirmam que a necessidade de se organizar institucionalmente em pastorais afro-brasileiras decorre de iniciativas diferenciadas de negros católicos na missão da Igreja. Esta informação está de acordo com a Conferência Nacional dos Bispos do Brasil.

Assim, a Igreja Católica volta-se para os afrodescendentes da comunidade quando incorporam seus elementos culturais e parte da cosmovisão africana nessa instituição religiosa. Assim, de acordo com a Conferência Nacional dos Bispos do Brasil (CNBB), a criação da Pastoral Afro-brasileira evidencia o direcionamento às demandas específicas no tocante às populações negras católica. As discussões levantadas nesses encontros são relativas à luta pela titulação de terras que foram quilombos, questões políticas e sociais. Entretanto, não são apenas afrodescendentes quem participam (SILVA, ÁVILA e MACIEL 2010).

Como consequência dessas relações sociais estabelecidas em âmbito religioso, temos a construção de redes e articulações que possibilitam o desenvolvimento socioeconômico e político dessas comunidades, além de melhorar a qualidade de vida. Outro elemento de suma importância para a Comunidade São João Batista é a tradição.

Quanto a Missa Afro na Comunidade, observou-se que a mesma é vivida com muita intensidade ressaltando o orgulho de ser comunidade negra, por meio do reavivamento da espiritualidade trazida da África. A missa é uma reflexão sobre o passado. A Comunidade conta a história de um povo negro, revive o seu sofrimento, sua luta e sua resistência. Cada momento da celebração é um convite à valorização de sua memória e sua cultura (SILVA, ÁVILA e MACIEL, 2010, p. 60).

Constata-se, dessa forma, que um dos aspectos mais importantes que possibilitam o entendimento sobre o sentimento de pertença está alicerçado no cultivo da tradição. Ou seja, no reforço do passado transmitido e compartilhado com as gerações futuras, fortalecendo o sentimento de afetividade entre esses.

Portanto, a religiosidade nesse contexto tem um papel social central, posto a influência que exerce sobre as atitudes, comportamentos, valores sociais e morais e sobre a vida material dos residentes da comunidade (SILVA, ÁVILA e 
MACIEL, 2010).

Realizando uma análise da trajetória política do ex-deputado federal, parlamentar e iurdiano Reginaldo Germano, relator do Projeto de Lei do Estatuto da Igualdade Racial na Câmara dos Deputados, Santos (2013) questiona sobre a possibilidade de se construir uma identidade negra numa religiosidade neopentecostal.

Utilizando do material legislativo produzido pelo deputado, bem como dos discursos proferidos pelo parlamentar para embasar sua análise, a autora objetivava pensar como se constituiu a relação entre as questões raciais e o Protestantismo (Pentecostalismo/Neopentecostalismo) (SANTOS, 2013).

Segundo Santos (2013) Reginaldo Germano chegou a Salvador/BA para atuar como pastor em 1997. Membro da Igreja Universal do reino de Deus (IURD) é candidato em 1998 pelo PMDB a deputado federal, contando com o apoio da IURD.Seguindo como membro da IURD e representante político, Germano atua como deputado federal pelo estado da Bahia entre os anos 1999 e 2006.

Oparlamentarvestia-secomindumentárias africanas e proferia discursos sobre demandas raciais, mas seu embasamento político e ideológico era neoliberal, tendo posicionamentos relativos aos da Direita. Durante sua trajetória política, passou por partidos como o Partido da Frente Liberal, Partido Progressista e o Partido do Movimento Democrático Brasileiro (SANTOS, 2013).

As pautas levantadas em seus discursos eram referentes majoritariamente aos direitos sociais dos negros e por melhores condições de vida desse grupo. Destacou-se na arena política quando foi chamado para ser relator da comissão que criou o Estatuto da Igualdade Racial. Assim, o deputado levantava as questões raciais e sociais que marginalizava a população negra sem, contudo, deixar de lado a defesa dos interesses da IURD. Santos (2013) ressalta que o posicionamento do deputado sobre as demandas da população negra pode ter sido motivado pelo preconceito racial vivenciado.

Embora seus discursos fossem mais voltados para as questões raciais - 66 eram relativos ao racismo e questões raciais e apenas 23 para aos interesses da IURD -, nos momentos em que os interesses religiosos e a identidade racial eram postos em conflito, seu posicionamento político voltava-se para os interesses da IURD. Dessa forma, a hostilização e o ataque as religiões de matriz africana eram visivelmente característicos de sua postura política quando colocada em pauta. Ser iurdiano consistia na negação das manifestações religiosas africanas (SANTOS, 2013). 
Não obstante, como afirma Santos (2013), o preconceito religioso de Germano não o impediu de arrecadar verbas para a implementação de programas e projetos ligados aos grupos das religiões afro. A sede do llê Ayê, por exemplo, foi construída com o auxílio do deputado iurdiano, que arrecadou verbas necessárias aos recursos. Outro aspecto que marcou a trajetória do deputado Germano foi sua boa relação com lideranças negras de renome no contexto político e social baiano, cuja participação nas audiências públicas sobre a reelaboração do Estatuto da Igualdade Racial era constante.

Outra iniciativa de Germano foi à criação de um movimento negro evangélico chamado MONEBA - Associação Nacional do Movimento Negro Evangélica, no qual reivindicava as demandas raciais amparado em preconceitos e convicções religiosas.

Em última instância, Santos (2013) levanta questionamentos contundentes a respeito da negritude e vínculos religiosos, tendo como base a trajetória política de Reginaldo Germano. Sendo assim, afirma que ser combatente das discriminações e intolerâncias que instituições religiosas de matrizes africanas são vítimas não significa a associação imediata do ser negro a essas práticas religiosas. Citando John Burdick (2002), a autora reflete as peculiaridades que permeiam o debate sobre as religiosidades e a identidade étnica negra.

Atualmente, há no Brasil um profundo antagonismo, sem praticamente nenhum canal de comunicação, entre o movimento negro organizado e o movimento pentecostal. Do lado do movimento negro, o pentecostalismo é visto como inimigo porque está impregnado da tradição religiosa européia e porque declarou guerra à religião afro. Enquanto isso, os pentecostais solidários com a luta contra o racismo sentem-se alienados do movimento negro por causa, entre outras razões, do compromisso deste último com as religiões afro. Trata-se, sem dúvida, de gigantescas barreiras ideológicas à colaboração entre os dois movimentos (BURDICK, 2002:20, p. 14).

Assim, com a lacuna de estudos referentes à diversidade cultural e religiosa no Brasil, buscamos realizar, no próximo item, um breve levantamento das principais revistas das Ciências da Religião para que possamos visualizar a situação em que se encontra o debate sobre o racismo e a identidade negra, denunciando a ausência desses estudos nas diversas religiosidades brasileiras e a centralidade que ocupam as análises sobre vivências religiosas de matriz africana em 
Raça, etnicidade e religião, pp. 132 - 155

detrimento das católicas e pentecostais. Além disso, os dados irão nos sugerir novas fórmulas de se compreender as comunidades afrodescendentes quando estas, afirmam novas identidades e novas práticas políticas e religiosas.

\section{LEVANTAMENTO DOS ESTUDOS EM CIÊNCIAS DA RELIGIÃO SOBRE IDENTIDADE NEGRA E RELIGIOSIDADE}

Tendo em vista a importância do debate das questões raciais no contexto institucional religioso, buscamos realizar um breve levantamento quantitativo nas principais revistas eletrônicas acadêmicas da Ciência da Religião e demais áreas de conhecimento cujas temáticas são abordadas. Para tanto, utilizamos como critério de seleção dos artigos a presença ou ausência das temáticas racismo e identidade negra relatadas nas publicações que questionam as experiências religiosas dos negros desde as Igrejas Pentecostais, passando pelas instituições católicas e de matriz africana. Posteriormente, o levantamento de dados referentes à cor e formação acadêmica dos pesquisadores cuja temática racial foi abordada alicerçada aos estudos sobre as diferentes manifestações religiosas.

Salientamos que o objetivo deste levantamento deve-se à importância do debate sobre as diversidades culturais e étnicas brasileiras alicerçadas às diferentes manifestações religiosas, cuja centralidade volta-se ao grupo social negro. Nesse sentido, acreditamos que as demarcações identitárias dos negros bem como todo o processo que constitui o "tornar-se negro"8 devem ser analisadas sobre todas as esferas da vida social deste grupo, incluindo a religiosa.

\subsection{RELIGIOSIDADE, RAÇA E ETNIA EM PERIÓDICOS DAS CIÊNCIAS DA RELIGIÃO}

Após realizarmos o levantamento quantitativo das revistas ANPUH (Revista Brasileira de História - Associação Nacional de História), da revista Horizonte (Revista de Estudos de Teologia e Ciências da Religião), Numen (Revista de Estudos e Pesquisa da Religião), PLURA-ABHR (Revista de Estudos de Religião

${ }^{8}$ O termo "torna-se negro" ficou reconhecido com a publicação do livro Tornar-se Negro de Neuza Santos (1983), que mostra como a perversa idéia de "limpeza do sangue" se faz presente no imaginário social do brasileiro, pois o discurso que associa a raça negra a miséria e inferioridade teve esta idéia como contrapartida, embranquecendo as relações sociais e afetivas. Além disso, a psicanalista realizou importantes contribuições para o estudo dos efeitos psicológicos do racismo ao negro. 
- Associação Brasileira de História das Religiões), Religião e Sociedade e Rever (Revista de Estudos da Religião)por meio das plataformas que disponibilizaram as publicações dos periódicos desde o primeiro lançamento - com exceção da revista Religião e Sociedade -, contabiliza-se o total de 2.287 artigos, cujo resultado representa a soma do número de periódicos de cada revista. Em contrapartida, o total de artigos, fóruns e comunicações publicados que englobam a temática religião e religiosidade aliado a etnicidade negra é de 62 periódicos. Temos, assim, o percentual de apenas 3\% de publicações sobre temáticas que abordam a cultura negra e os diferentes fenômenos religiosos.

O gráfico abaixo ilustra em percentual e valores absolutos a totalidade de artigos publicados em cada revista e a totalidade de artigos publicados sobre o tema religiosidade, raça e etnia nas Ciências da Religião.

\section{Gráfico 1 - Publicações das revistas na área de Ciência da Religião}

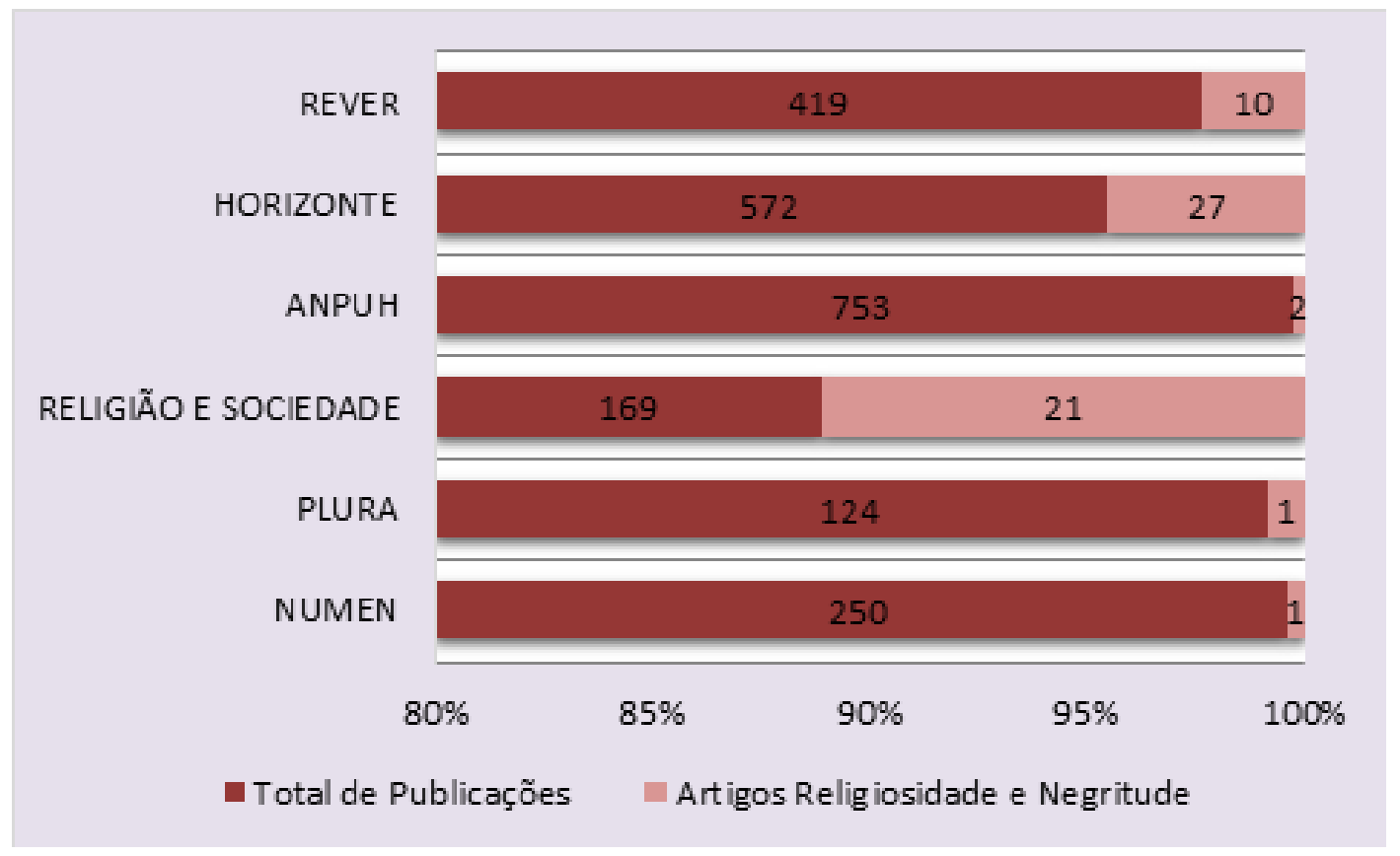

Fonte: Pesquisa Própria, 2017

Através do gráfico, nota-se que a única revista cujo percentual de artigos sobre identidade negra e religiosidade ultrapassou 10\% foi a Religião e Sociedade, tendo o total de 169 periódicos lançados e 21 artigos cujas temáticas sobre raça, cultura e religião foram abordadas (12\%). Temos, assim, a ausência ou quase que inexistência do debate sobre as questões étnicas e raciais no campo científico 
acadêmico que engloba a Ciências da Religião e a História das Religiões.

Para melhor demonstrarmos o panorama das 62 publicações, iremos realizar uma breve análise de conteúdo desses artigos para compreendermos que temáticas são mais abordadas, quais religiões ou religiosidades foram estudadas com mais ênfase e quais relações foram estabelecidas entre racismo, identidade étnica negra e religião. Posteriormente, iremos identificar os autores mais citados pelos cientistas da religião - indo desde os sociólogos, historiadores e antropólogos.

Ao analisarmos os 62 artigos - que equivale à soma de periódicos publicados em cada revista -, observamos que embora todos perpassem pelas questões étnico-raciais negra, as religiosidades abordadas variavam. Sendo assim, após a leitura dos títulos, resumos e palavras-chave, notamos que cinco abordagens temáticas se sobressaíram, sendo elas: Religiões de matriz Africana; Religião Católica; Religiões Protestante, Pentecostal e Neopentecostal; Religiões no Brasil e Religiões Afro-indígenas. Ressalto que a ordem das temáticas está de acordo com a centralidade que cada uma ocupou nesses estudos, tendo as religiões de matriz africana maior espaço nos debates em detrimento das religiões afro-indígenas.

Os artigos cuja temática centralizava-se nas Religiões de Matrizes Africanas alicerçada as etnicidades negra tinham abordagens diversas, mas os processos de desafricanização da Umbanda e de reafricanização do Candomblé e demais religiões afro-brasileiras foram as mais ressaltadas no que concerne a preservação da identidade negra e o sentimento de pertença grupal. Sendo assim, são artigos que tiveram uma relação mais direta com as problemáticas que envolvem o racismo.

Nos periódicos que estudam o Catolicismo e suas diferentes formas de instituição sócio-religiosa, nota-se que as abordagens majoritárias referiam-se as comunidades eclesiais de base, aos remanescentes de quilombo, as irmandades negras e ao Juazeiro.

Já na temática que engloba o Protestantismo, Pentecostalismo e o Neopentecostalismo, as análises dos artigos focam nos temas da violência, da criminalidade, da periferia urbana e da diversidade pentecostal. Observei que nestes periódicos, o racismo e suas nuanças não ocuparam papel central no debate, pois as variantes socioeconômicas tiveram maior enfoque nos estudos.

Sobre Religiões no Brasil, os periódicos debatem em sua maioria a respeito da diversidade cultural no Brasil, além do pluralismo religioso. E as publicações 
sobre as Religiões Afro-indígenas analisam a cultura negra e ameríndia, a teologia negra e indígena, o sincretismo religioso e a interculturalidade.

Nesse sentido, mesmo com o baixo percentual de publicações que interrelacionam os estudos sobre as manifestações religiosas e as diferentes formas de preservação étnica, podemos observar que há uma gama de temas a serem explorados, que perpassam determinantes sociais, econômicos, culturais e religiosos.

No que concerne ao jogo de palavras-chave que foram mais utilizados nos 62 artigos que relatam a religiosidade e a etnicidade negra, temos um conjunto de palavras que estão postas de modo decrescente no que diz respeito ao número de vezes em que foram utilizadas, como demonstra o quadro a seguir:

\section{PALAVRAS-CHAVE MAIS UTILIZADAS NOS 62 ARTIGOS QUE ESTUDAM A RELIGIOSIDADE E A ETNICIDADE NEGRA}

Religião; Religião-Afro; Candomblé; Pentecostalismo; Catolicismo e Igreja Católica; Identidade; Negro; Cultura; Favela; Periferia; Pluralismo Religioso; Pluralismo Cultural; Umbanda; Africana; Negritude e Interculturalidade.

Observamos também que há um diálogo entre as referências bibliográficas desses 62 artigos que abordam raça e religiosidade com autores que estudam as questões étnico-raciais, sendo predominante a citação de alguns autores como ilustra a tabela abaixo:

\section{REFERÊNCIAS BIBLIOGRÁFICAS DE AUTORES QUE ESTUDAM AS QUESTÕES ÉTNICO-RACIAIS NOS 62 ARTIGOS}

Kabengele Munanga, Lívio Sansone, Paul Gilroy, Stefania Capon, Ronaldo L Sales, Roger Bastide, Kathryn Woodward, Walter Praxedes, Júlio Jacobo Waiselfisz, Lilia Mortiz Schwarcz, Yvonne Maggie e Claudia Barcellos Rezende,John Burdick.

Além desses, antropólogos, sociólogos, cientistas políticos, filósofos e geógrafos também são citados nos trabalhos, a exemplo de: 
Vicente Fideles Àvila,Clifford Geertz, Milton Santos, Noberto Bobbio, Pierre Bourdieu, Roberto Motta, Marx Weber, Émile Durkheim, Florestan Fernandes, Stuart Hall, Antonio Gramisci, Marilena Chauí, Antônio S, Guimarães, Jurgen Habermas, Renato Ortiz, Michael Foucault, Peter Burke, Zygmunt Bauman.

Portanto, com a explanação de apenas alguns dos artigos que abordam a temática raça, religiosidade e etnia, podemos afirmar que a exploração sobre o tema nos possibilita percorrer caminhos variados para melhor compreendermos as relações e vínculos estabelecidos entre cultura, sociedade e religião, principalmente no que concerne ao grupo étnico negro.

\subsection{DISTRIBUIÇÃO DOS PESQUISADORES SEGUNDO A COR}

Com o intuito de identificarmos quem são os pesquisadores que realizaram seus estudos centralizando nas temáticas sobre negritudes, etnicidades e religiosidades, buscamos informações sobre a cor e a trajetória acadêmica de cada um, tendo como ferramenta de acesso a estes dados a atualização do currículo lattes (site Plataforma Lattes) ${ }^{9}$. Nesse sentido, com a ausência de algumas informações não atualizadas pelos pesquisadores, obtivemos lacunas em alguns resultados.

Para melhor problematizarmos a vigente escassez de periódicos que abordam as questões raciais e sociais nos diferentes fenômenos religiosos, distribuímos os pesquisadores segundo a cor, tendo as categorias preto, pardo e branco.

Houve um total de 77 pesquisadores que abordaram a etnicidade negra e a religiosidade em seus artigos, sendo disponíveis as informações sobre a cor de 40 desses (22 brancos, 11 pardos e 07 pretos). Sendo assim, obtivemos 52\% das informações referentes à cor dos pesquisadores.

9 Disponível em:<http://buscatextual.cnpq.br/buscatextual/busca.do?metodo=apresentar > Acesso em: 28/01/2017. 
Gráfico 2 -Distribuição dos Pesquisadores segundo a cor

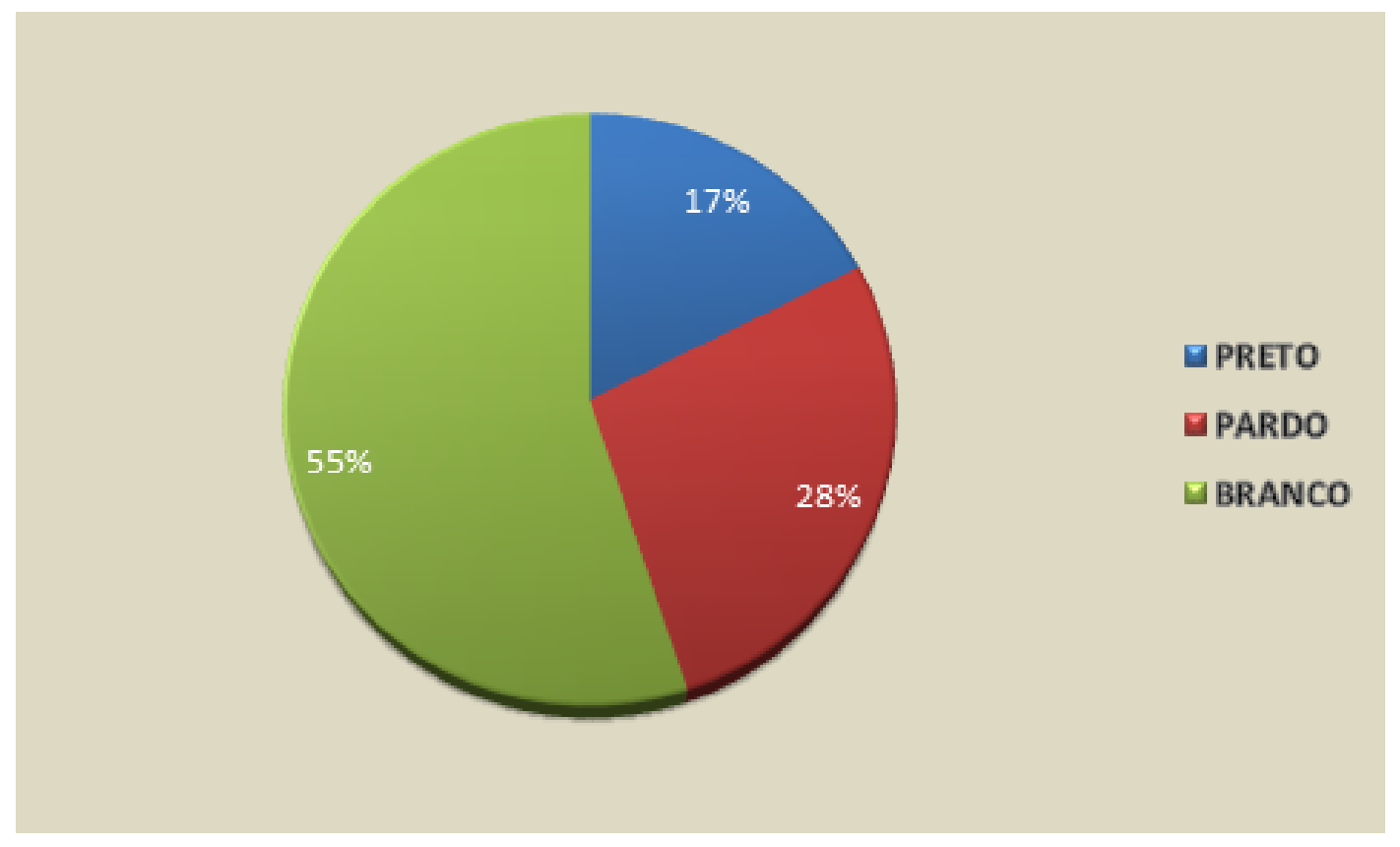

Fonte: Pesquisa Própria, 2017

O gráfico acima constata que, aliada à problemática da ausência de artigos publicados nas diferentes revistas de estudos teológicos e científicos da religião, há a predominância de pesquisadores brancos que estudam as questões raciais e as constituições étnicas no cenário das religiosidades. Temos, portanto, para além do não protagonismo negro sobre as análises referentes às suas vivências e pertencimento étnico, o baixo percentual de intelectuais negros que formam o corpo científico dessas pesquisas (28\% pretos e 17\% pardos), podendo-se levantar algumas hipóteses sobre a justificativa dos baixos percentuais de periódicos que discutem a religiosidade e a etnicidade negra (12\%).

Sugerimos relacionar a pouca formação de intelectuais ${ }^{10}$ negros nos espaços acadêmicos aos poucos periódicos que analisam o racismo não como uma das variantes, mas como determinante central para as desigualdades raciais e sociais. Outro fator que pode estar relacionado a estes percentuais são os problemas

${ }^{10}$ Marçal (2012) em um dos capítulos que relata o papel social dos intelectuais orgânicos negros na história, relembra célebres nomes de pesquisadores e acadêmicos negros no cenário brasileiro. Dentre eles, nomes como Luiz Gama (1890-1882), José Correia Leite (1900-1989), Solano Trindade (19081974), Edson Carneiro (1912-1972), Abdias Nascimento (1914-2011), Guerreiro Ramos (1915-1982), Oliveira Silveira (1941-2009), Lélia Gonzalez (1935-1994), Beatriz Nascimento (1942-1995), Hamilton Cardoso (1953-1999), além de Neusa Santos (1951-2008). 
estruturais que dificultam o acesso da população negra à educação pública, e por extensão, a universidade. Outra hipótese refere-se aos poucos quadros de professores negros e de grupos dedicadas às pesquisas com negros no meio acadêmico.

\section{3.ÁREAS DE GRADUAÇÃO E ESPECIALIZAÇÃO DOS PESQUISADORES}

Ao analisarmos a trajetória acadêmica dos pesquisadores que abordaram em seus artigos a identidade étnica negra nas diferentes manifestações religiosas, optamos por separar a formação em duas: graduação e especialização (Pósgraduação ou Mestrado). Para tanto, tivemos na graduação 17 áreas de formação. Com o total de 77 pesquisadores, não obtivemos a informação da graduação de 07 desses. O gráfico abaixo ilustra em valores absolutos o total de graduações realizadas nas respectivas áreas.

Gráfico 3 -Áreas de Graduação dos Pesquisadores Fonte:Pesquisa Própria, 2017.

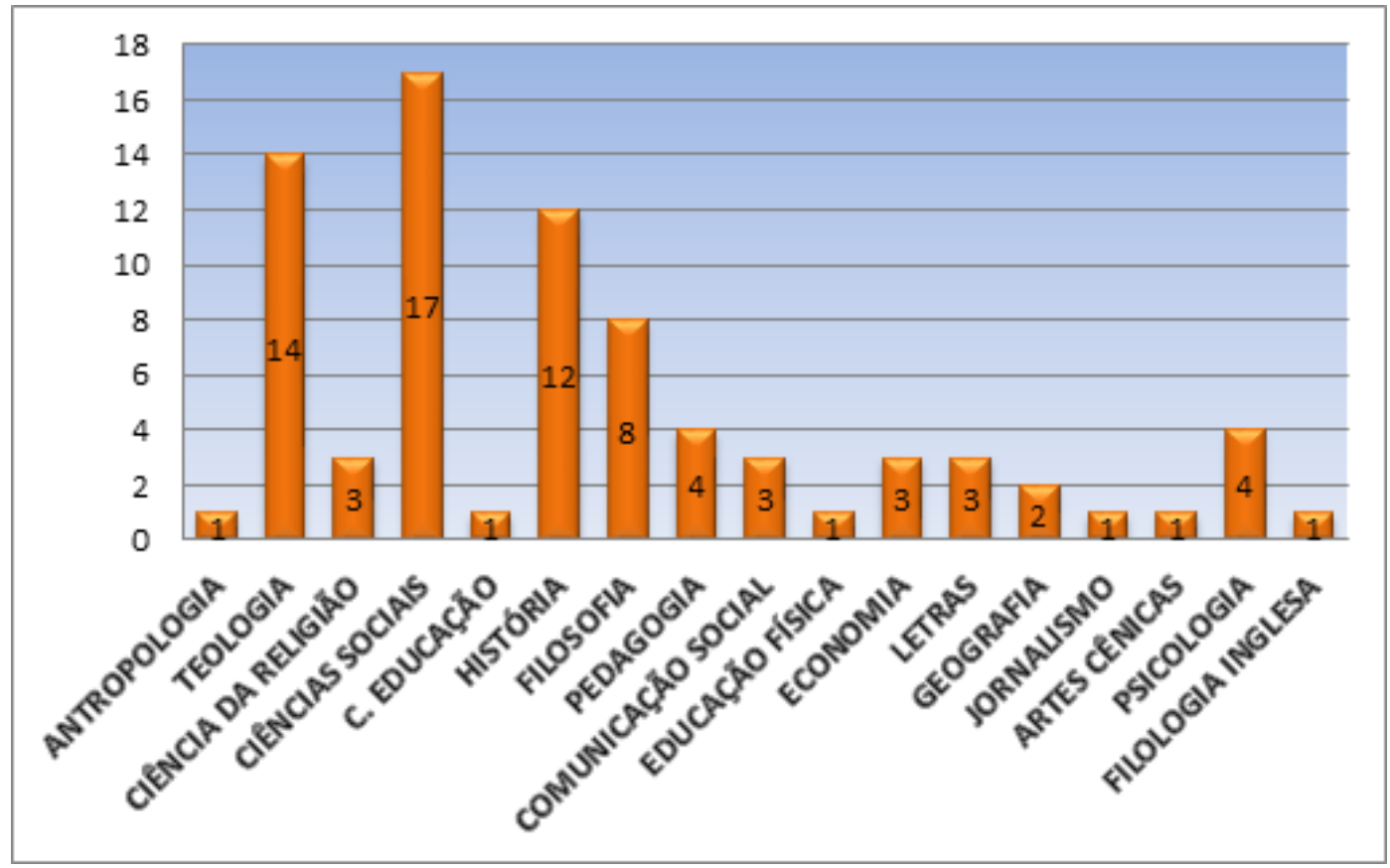

Temos assim, quatro áreas de formação com maiores percentuais, sendo elas: Ciências Sociais (22\%), Teologia (18\%), História (15\%) e Filosofia (10\%). 0 gráfico abaixo demonstra os percentuais. 
Gráfico 4- Percentual das principais áreas da Graduação dos Pesquisadores

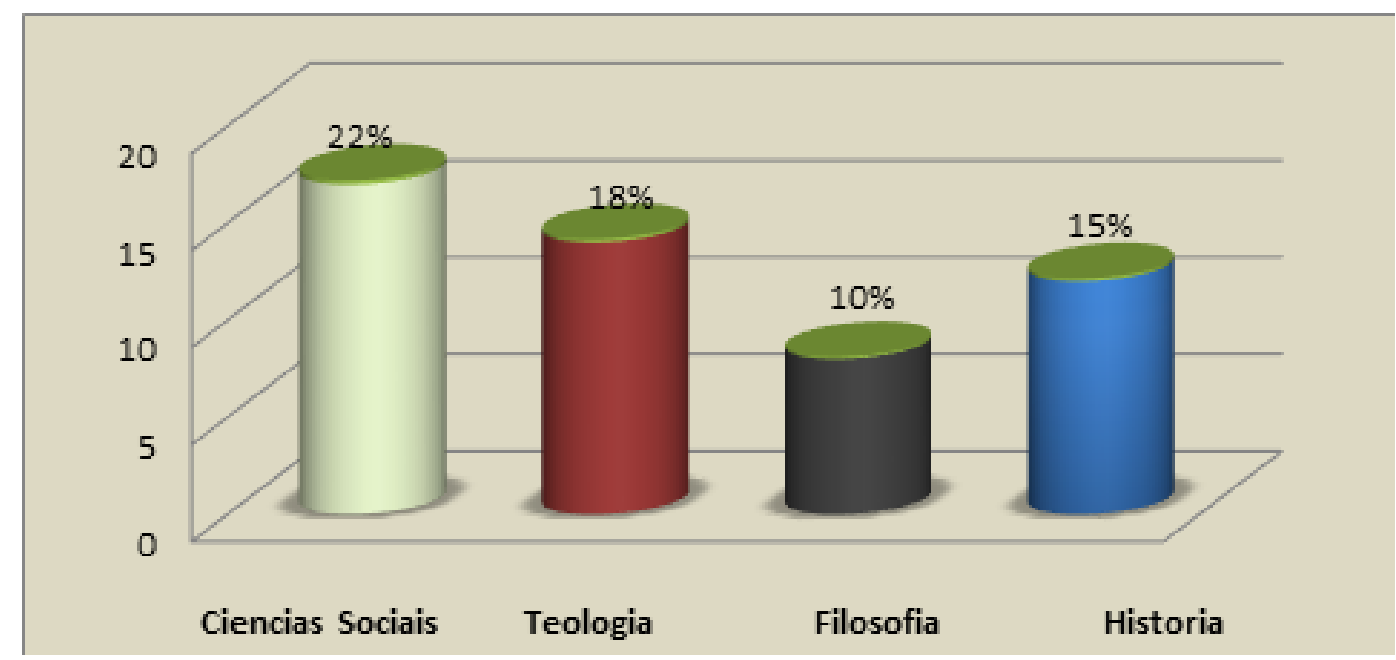

Fonte: Pesquisa Própria 2017.

No que concerne às especializações (Pós-graduação e Mestrado), identificamos 21 áreas de formação, sendo as de maiores percentuais a Antropologia (12\%), Teologia (11\%), Antropologia Social (9\%), Ciência da Religião (12\%) e Ciências Sociais (15\%). Ressalto que, semelhante à graduação, as especializações dos pesquisadores cuja temática sobre identidade negra, etnicidade e religiosidade foram estudadas são em maior número das Ciências Sociais. Não obtivemos a informação da especialização de 13 dos 77 pesquisadores.

Gráfico 5- Percentual das principais áreas de Especialização dos Pesquisadores

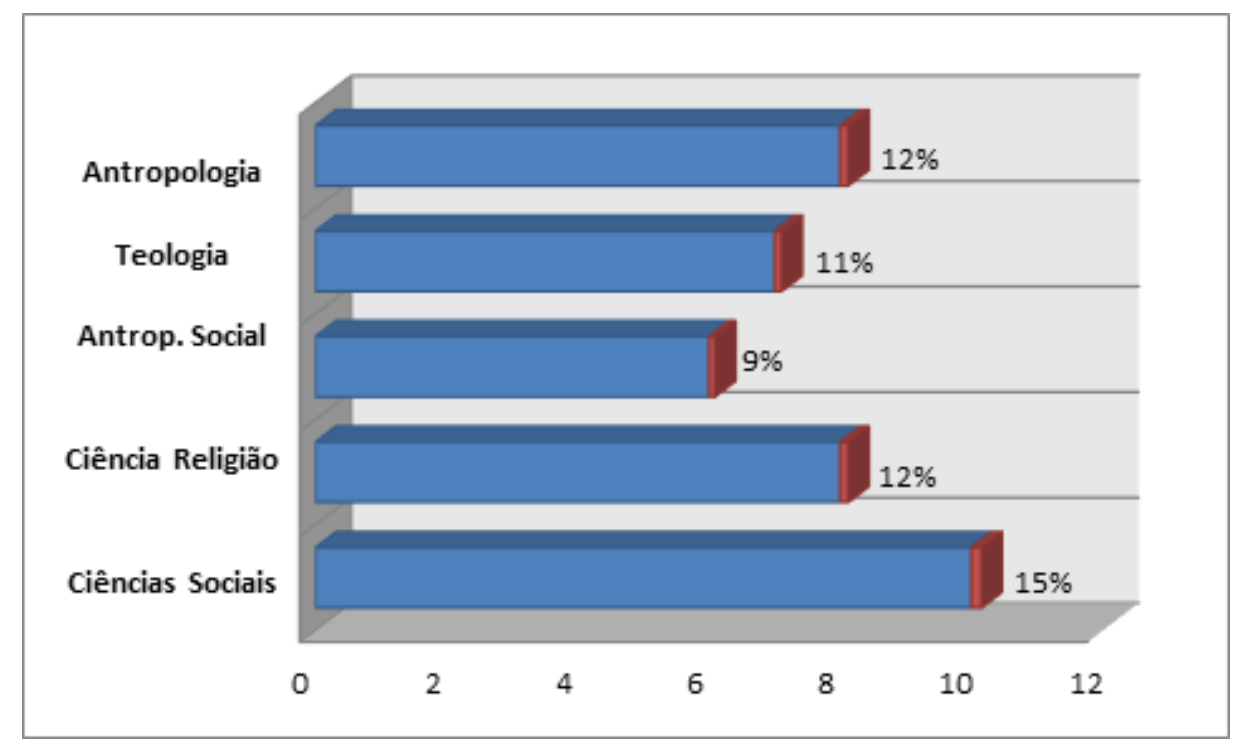

Fonte: Pesquisa Própria, 2017. 
Dessa forma, de acordo com os dados apurados, podemos constatar o baixo percentual de artigos que abordam questões concernentes ao pertencimento étnico pelos cientistas da religião, denunciando a falta de intelectuais negros para a contribuição ao debate e a predominância de sociólogos pesquisadores sobre o tema.

\section{CONSIDERAÇÕES FINAIS}

Neste artigo, pudemos debater brevemente sobre a relevância dos estudos de etnicidade negra para maiores explorações analíticas no campo das Ciências das Religiões. Compreendemos que no contexto multiculturalista característico deste século, há várias possibilidades de se afirmar a negritude. Sendo assim, conceder legitimidade e autenticidade a negritude/africanidade somente quando o negro expressa sua fé em instituições religiosas afro-brasileiras, é um engodo.

Além disso, partindo do princípio de que a afirmação de uma identidade é histórica - ou seja, está situada em um tempo e espaço específicos -, esta demarcação de identidades característica do momento é de suma importância para o processo de construção de identidade negra, que envolve diferentes realidades sociais e, por isso, distintas estratégias.

Portanto, é imprescindível analisar o fenômeno religioso e como ele se reverbera na vida social, cultural e política do negro de diferentes formas, tendo em vista as vivências, perspectivas e contextos sociais multifacetados em que estão inseridos. Ressaltamos também que esta é uma pesquisa exploratória. Sendo assim, os resultados obtidos são apenas parciais e merecem estudos mais profundos.

\section{REFERÊNCIAS BIBLIOGRÁFICAS}

SEYFERTH, Giralda. A Invenção da Raça e o Poder Discricionário dos

Estereótipos.Anuário Antropológico/93. Riode Janeiro:Tempo Brasileiro,Museu Nacional, UFRJ, 1995.

GUIMARÃES, Antônio S. A.Preconceito racial: Modos, Temas e Tempos. Cortez Editora, Dados Internacionais de Catalogação na Publicação (CIP). Câmara Brasileira do Livro, SP, Brasil, 2ª Edição, 2012. 
SCHWAREZ, K. Lilia. Questão Racial e Etnicidade.In: Miceli (org). O que lês na Ciência Social brasileira (1970-1995). São Paulo, Brasília: Editora Sumaré ANPOCS/ CAPES. 1999.

SANTOS, Márcio A.Negritudes posicionadas: as muitas formas da identidade negra no Brasil.2010.

MOURA, Clóvis. HISTÓRIA DO NEGRO BRASILEIRO. Série Princípios, 1989.

SILVA, Mônica Cristina A. de Matos da. ÁVILA, Vicente F.MACIEL, Josemar de C.Religiosidade e sentimento de pertença: considerações acerca da festa em homenagem a São João Batista e da missa afro na comunidade remanescente de quilombo "São João Batista" - Campo Grande/MS.Revista Brasileira de História das Religiões. ANPUH, Ani II, N. 8, Set. 2010

SANTOS, A. Martins. Identidade Negra e Neopentecostalismo: $\bigcirc$ caso Reginaldo Germano.ANPUH, 2013

MARÇAL, José A. A Formação de intelectuais negros (as): políticas de ação afirmativa nas universidades brasileiras, Belo Horizonte, Editora Nandyala Livros. . 2012.

FERNANDES, Florestan. A Integração do negro na sociedade de classe. $V .1,5^{a}$ Ed. São Paulo: Globo 2008.

FILHO, José H. das F.A vocação da periferia pelo pentecostalismo e o negro pentecostal na área do Mutirão em Bayeux em meio à segregação e pobreza. PLURA, Revista de Estudos de Religião. 2016

SILVA, Nelson do Valle. Cor e o processo de realização socioeconômica. In: HASENBALG, Carlos A; Silva, Nelson do Valle (Orgs) Estrutura social, mobilidade e raça. Rio de Janeiro: Vértice, 1988. P. 144-163.

TELLES, Edward. Racismo à brasileira: uma nova perspectiva sociológica. Rio de Janeiro: ReluméDumará/ Fundação Ford, 2003.

HANCHARD, Michael George. Orfeu e o poder: o movimento negro no Rio de 
Raça, etnicidade e religião, pp. 132 - 155

Janeiro e São Paulo (1945-1988). RJ: EdUERJ, 2001.

MUNANGA, Kabengele. Política de ação afirmativa em benefício da população negra no Brasil: um ponto de vista em defesa de cotas. In: SILVA, Petronilha BeatrizGonçalvez; Silvério, Valter Roberto (Orgs). Educaçãoe ações afirmativas: entre a injustiça simbólica e a injustiça econômica. Brasília: Instituto nacional de Estudos e Pesquisas Educacional Anísio Teixeira, 2003. 